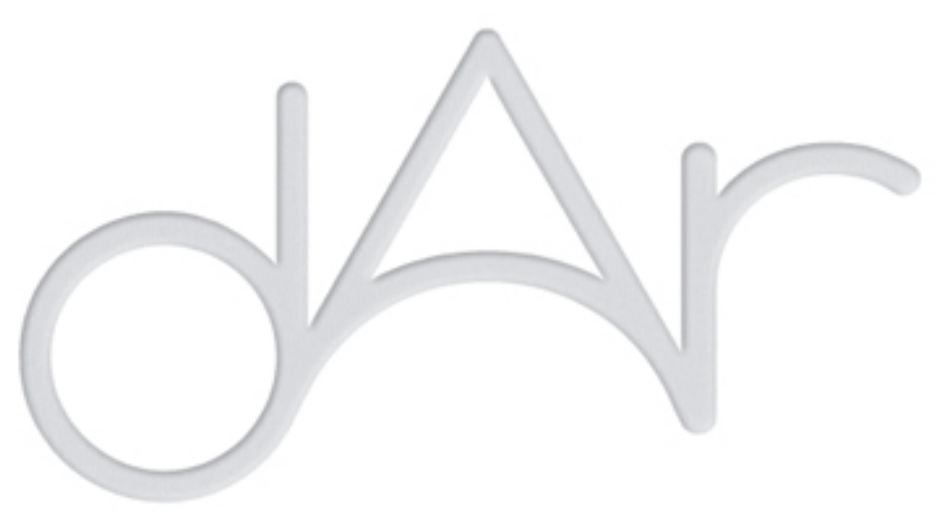

\title{
A Casa de Taipa no Litoral Sul de Alagoas: Registros Escritos e Visuais
}

Autor(es): $\quad$ Silva, Maria Angélica da; Alcides, Melissa Mota; Jardim, Alice Mesquita

\section{Publicado por: CEAUCP}

URL

persistente: URI:http://hdl.handle.net/10316.2/9135

\section{Accessed : $\quad$ 26-Apr-2023 15:58:11}

A navegação consulta e descarregamento dos títulos inseridos nas Bibliotecas Digitais UC Digitalis, UC Pombalina e UC Impactum, pressupõem a aceitação plena e sem reservas dos Termos e Condições de Uso destas Bibliotecas Digitais, disponíveis em https://digitalis.uc.pt/pt-pt/termos.

Conforme exposto nos referidos Termos e Condições de Uso, o descarregamento de títulos de acesso restrito requer uma licença válida de autorização devendo o utilizador aceder ao(s) documento(s) a partir de um endereço de IP da instituição detentora da supramencionada licença.

Ao utilizador é apenas permitido o descarregamento para uso pessoal, pelo que o emprego do(s) título(s) descarregado(s) para outro fim, designadamente comercial, carece de autorização do respetivo autor ou editor da obra.

Na medida em que todas as obras da UC Digitalis se encontram protegidas pelo Código do Direito de Autor e Direitos Conexos e demais legislação aplicável, toda a cópia, parcial ou total, deste documento, nos casos em que é legalmente admitida, deverá conter ou fazer-se acompanhar por este aviso.

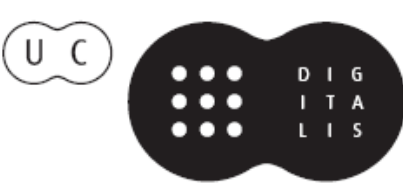


$6^{\circ}$ Seminário de Arquitectura em Terra em Portugal ( $6^{\circ}$ ATP) $9^{\circ}$ Seminário Ibero-americano de Construção e Arquitectura com Terra (9 SIACOT)

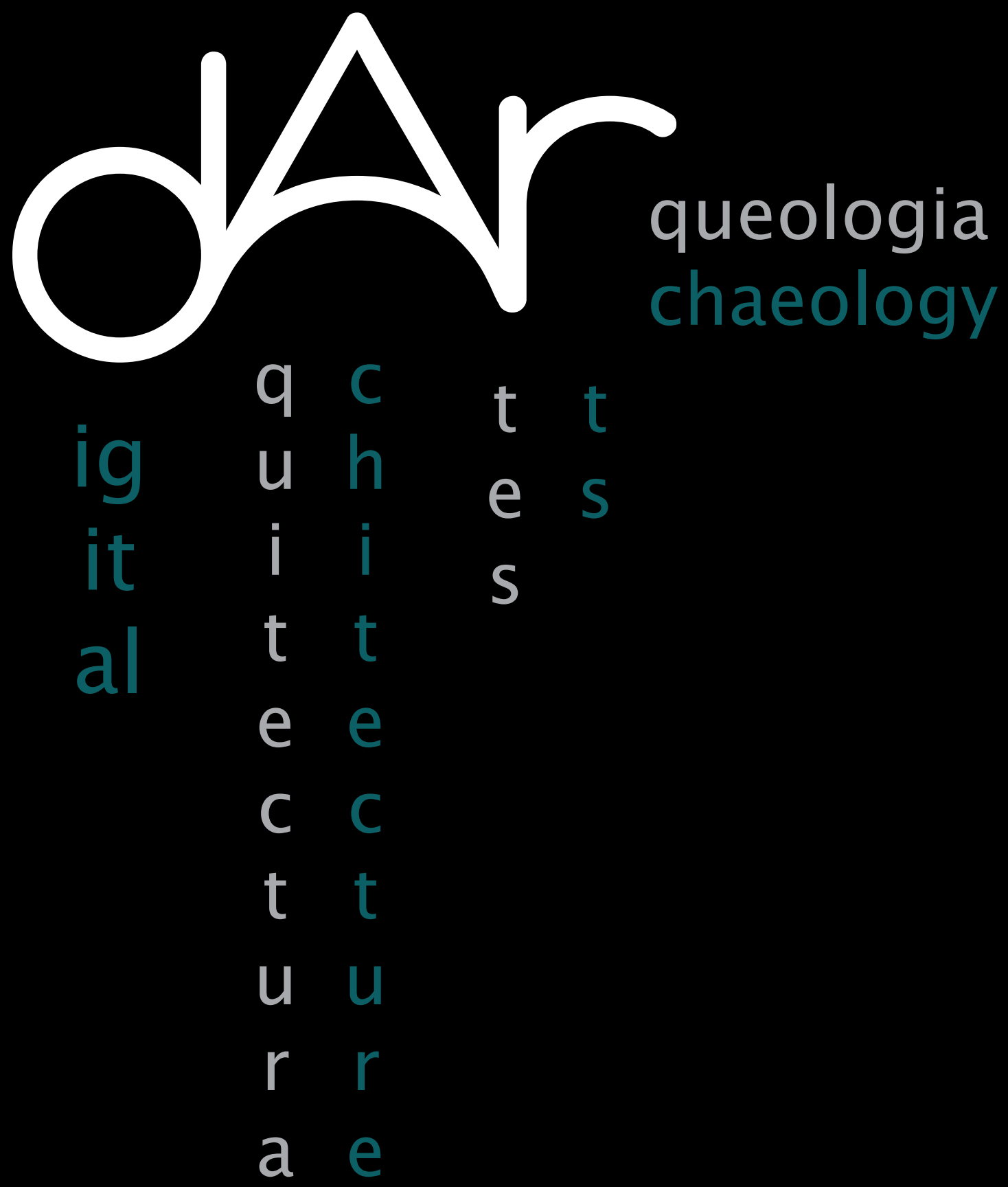




\title{
A CASA DE TAIPA NO LITORAL SUL DE ALAGOAS: REGISTROS ESCRITOS
}

E VISUAIS

\author{
Maria Angélica da Silva* (Brazil) \\ Faculdade de Arquitetura e Urbanismo, Universidade Federal de Alagoas \\ Melissa Mota Alcides** (Brazil) \\ CESMAC - Centro de Estudos Superiores de Maceió, Faculdade de Arquitetura e Urbanismo \\ Alice Mesquita Jardim*** (Brazil) \\ UFAL - Grupo de Pesquisa Estudos da Paisagem, Faculdade de Arquitetura e Urbanismo
}

\section{RESUMO}

A técnica da taipa de sopapo consiste na produção de um arcabouço de madeira prenchido com terra. Foi implantada durante o período de colonização do Brasil, pelos portugueses, possivelmente trazida da África, e ainda é utilizada no Nordeste do Brasil. Nos pequenos povoados, nas áreas rurais e mesmo na periferia de grandes cidades, surgem as casas edificadas com esta técnica, prolongando-se às vezes por ruas e partes de bairros. Ainda restam exemplares construídos dentro de um proceder que atravessou os séculos mas, com o avanço da consciência ecológica e dos próprios mecanismos de proteção de determinadas áreas por seu valor ambiental - que proíbem a extração da madeira do mangue, por exemplo - e outras modificações sócio culturais em andamento no Brasil, ocorreram modificações no processo construtivo. Tais mudanças, muitas vezes resultam em edificações de caráter bastante frágil. Portanto, vislumbra-se em horizonte próximo o ocaso desta prática construtiva, o que demanda um registro urgente dos procederes vinculados à mesma.

A historiografia acerca da arquitetura de terra no Brasil, em especial de suas técnicas, ainda é bastante escassa. Contudo, a presença material das casas de taipa permite que elas mesmas, na sua existência concreta, sirvam de ferramenta de investigação. Além disto, o recurso à história oral e os registros de caráter audio-visual têm se apresentado como formas bastante operacionais de resgatar informações para a escrita de uma história da tecnologia da arquitetura vernacular, ao mesmo tempo em que constituem, em si mesmos, documentos de memória.

O objetivo desta comunicação é a apresentação dos resultados obtidos em pesquisa realizada no povoado de Poxim, situado ao sul de Alagoas, Brasil, onde foi possível o registro de importantes aspectos do patrimônio material e imaterial vinculados à produção da taipa, tanto na construção de casas de moradia como em "casas de farinha", locais de fabrico de um alimento básico na refeição brasileira. A investigação resultou em um trabalho acadêmico textual e em registros no formato áudio visual.

Palavras-chave: Arquitetura em terra, taipa, patrimônio imaterial.

\footnotetext{
*mas@cnpq.br

**motamelissa@yahoo.com.br

***alicejardim@gmail.com
} 


\section{A ARQUITETURA DE TERRA NO BRASIL}

Dentre as técnicas mais representativas da arquitetura de terra, o processo de construção mais utilizado no Brasil, sobretudo no Nordeste e em Minas Gerais a partir do século XVI é a taipa de mão, sopapo ou pau-a-pique. Os materiais empregados na construção são diversos, dependendo da disponibilidade de cada região. Ainda podemos encontrar a quincha ou bahareque, a taipa de pilão e o adobe. Atualmente, porém, todas essas técnicas encontram-se em desuso e, consequentemente, a importância do seu registro através da história oral e da utilização dos recursos áudio-visuais, tornase urgente.

As casas de taipa, como são chamadas no Nordeste, são construídas com as coisas que a terra dá: o barro, a água, os finos galhos de algumas espécies arbóreas, as palmas ou palhas das palmáceas como o coqueiro. E, o processo construtivo em si, coloca-se como uma importante via de acesso ao conhecimento de valores, à identificação com o local de morada, à maneira de idealizar um novo espaço, materializado, e do modo de vida das pessoas que habitam pequenos povoados em diferentes localidades, interioranas ou costeiras.

Ao que se refere aos aspectos técnicos, a taipa é uma antiga técnica construtiva consistindo em paredes erguidas a partir de terra úmida socada em moldes (a taipa de pilão) ou de tapamento. Constitui-se de finos e longos galhos que serve de estrutura da parede vedada com barro. Geralmente as casas de taipa são cobertas de palha ou de telha cerâmica, neste último caso, quando os donos das moradas têm mais recursos financeiros.

As etapas de construção que envolvem a edificação em taipa são ricas e variadas. Podemos citar o envarado, o barreiro e o tapamento como as fases mais importantes. Com relação ao tapamento, podemos dizer que esta etapa possui um aspecto lúdico que se torna evidente com o clima de festa durante o trabalho com cantigas e brincadeiras entre os participantes. $\bigcirc$ beneficiário do tapamento oferece bebida e comida aos parentes e/ou amigos aos que cooperam nesta tarefa. Pelo trabalho no tapamento de uma casa de taipa não há retribuição direta em dinheiro.

Dessa forma, podemos perceber a riqueza e a variedade de aspectos sociais, antropológicos e culturais que envolvem o fazer da casa de taipa, motivo pelo qual - Grupo de Pesquisa Estudos da Paisagem (registrado no CNPq desde 1998) e sediado na Faculdade de Arquitetura e Urbanismo da Universidade Federal de Alagoas, realizou a pesquisa intitulada: Modos de Construir, Modos de Alimentar: Memórias da Paisagem Caeté nas Alagoas, cujo principal objetivo era mapear e registrar as práticas do patrimônio imaterial para fins de tombamentos futuros, com recursos advindos do Instituto do Patrimônio Histórico e Artístico Nacional, no povoado de Poxim (Coruripe, Alagoas, Brasil). Dentre as práticas do patrimônio imaterial mapeadas, destacamos neste artigo o registro das etapas construtivas que envolvem a edificação em taipa.

\section{POXIM E A TAIPA}

O sul de Alagoas configura-se enquanto uma porção do território que apresenta uma vicejante dimensão histórico-cultural. Além do emblemático acontecimento canibalístico envolvendo os índios Caetés e o Bispo Sardinha, catequista português, no século XVII, as terras desta parte do Nordeste foram ocupadas inicialmente pelos colonizadores portugueses e, seguidamente, pelos holandeses que, para além dos feitos bélicos, nos deixaram um importante legado de imagens, objetos, escritos e fragmentos da história que vencerem o tempo e registraram a história e a cultura deste território. Artistas e cientistas como Frans Post, Albret Eckhout, George Marcgrave e Guilherme Piso produziram imagens da paisagem nordestina nos séculos XVI e XVII privilegiando o recorte geográfico em questão e escritos ondem descrevem, dentre outros aspectos, os materiais naturais vinculados à arquitetura vernacular, como observamos mais especificamente no caso da descrição do 
urucuri iba (Siagrus coronata L.): "Os ramos desta árvore ou folhas servem para cobrir cabanas e para fazer amarras são muito flexíveis" (Marcgrave, 1942, p. 123). Essas amarras possivelmente eram utilizadas para deixar mais firmes o varado das casas de taipa, dentre outras utilizações.

Quanto às palhas, elas são mencionadas no relato de Marcgrave, vinculando-as às edificações:

"Carana iba. Copaíba. Ibixuma. Coapoiba. Buripicaiba . I biruba. Maratatabiba. CARANA IBA e ANANACHICARIRI (termos indígenas). [Coqueiro] Na extremidade de cada ramo, se acha uma folha redonda, dotada de pregas como um guardachuva de mulher (gallis parasol), de cor verde; da extremidade até quase o meio é dividida em muitas outras folhas carinadas, semelhantes às folhas da tamareira. (...) As folhas servem para cobrir choupanas e para o fabrico de cestos; com a madeira fazem-se cercados para se prenderem ovelhas e animais de carga; os portugueses os denominam Curraes." (Marcgrave, 1942, p. 130)

Outra folha também referenciada na literatura e largamente empregada até os dias de hoje na cobertura das casas é a do coqueiro:

"Quando vão construir uma casa, levantam primeiro os esteios e escoras, estendem sobre eles um ripado sobre o qual armam o telhado, coberto de telhas ou de folhas de coqueiro. Vivem nessas habitações." (Barléus, 1977, p. 72)

O registro das espécies vegetais utilizadas na construção de terra, encontrado na obra holandesa, foi confirmado através de um trabalho de história oral realizado com os habitantes da região. Sobre a utilização das palhas nas casas de taipa, Dona Maria José dos Santos informou que:

"aqui as casa é tudo de paia, aqui só não, no mundo por aqui nessa redondeza de praia, até onde eu moro, é tudo casa de paia, tirava a paia, acabar abria, eu mermo, uma casa que eu tinha, eu quem abriu a paia todinha pra cobrir a casa (...). Era de paia rosadinha, depois foi que o povo foi... se aletrando, aí pegaram o tapado de barro, tapadinha de barro (...). Lá no Miai onde eu morei e me criei, era. Foi todo mundo casinha de paia, (...) aí pegaram fazer a casinha de barro, outro arrumava a esteira, cobria, outro acobria de paia." (Dona Maria José dos Santos, 2006)

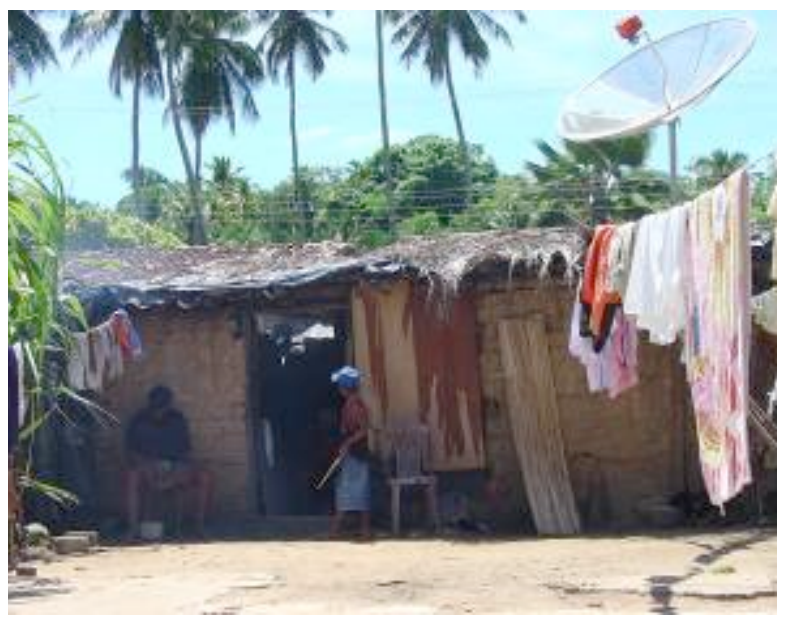

Fig.1. Casas de taipa cobertas com palha de coqueiro (créditos: acervo do Grupo de Pesquisa Estudos da Paisagem, 2008)

Fazendo parte deste espaço natural registrado pelos colonizadores portugueses e holandeses, encontra-se o povoado de Poxim, município de Coruripe, integrante do extremo sul de Alagoas. Esta localidade, e outras vizinhas, à primeira vista, configuramse como incipientes, com arruado pouco definido, casario singelo, morada de pessoas simples, que mantêm pouco contato com regiões economicamente mais desenvolvidas. No entanto, guardam evidências de um passado distante, registrado nos relatos dos colonizadores viajantes, fragmentos na longa duração, concretos e imaginários, que ainda pontuam a paisagem e a vida do lugar.

Poxim foi fundada no início do século XVII, estrategicamente posicionada entre duas importantes vilas dos primeiros séculos coloniais: Santa Maria Madalena da Lagoa 
do Sul e Penedo do São Francisco, fato que atesta a sua importância, sendo elevada a Vila Real em dez de fevereiro de 1733. Território inicialmente composto por grandes extensões de florestas atlânticas, em Poxim, na atualidade, as matas se inscrevem como lacunas no território perceptivo dos moradores. Antes da cana, cobertura vegetal predominante na zona da mata alagoana, a paisagem era composta por vastas áreas de terra cobertas por árvores de incontáveis espécies. Mas o tempo, que é uma variável fundamental sobre a paisagem, também deixou marcas no horizonte da paisagem do povoado. Hoje, em Poxim, a cana se aproxima da área povoada. De modo semelhante, no sítio habitado, o tempo também deixa marcas e a casa de taipa, se inscreve discretamente no conjunto arquitetônico, dando lugar às casas de blocos de cimento ou tijolos de barro, sendo reduzido gradualmente o número de casas de taipa cobertas com palha de coqueiro. Entretanto, os moradores mais antigos das localidades pesquisadas, ao serem indagados sobre a paisagem do passado, dão importância a este tipo de morada não apenas pelas vantagens em relação ao custo de sua edificação ou pela sua materialidade como teto que abriga, mas, sobretudo, por tudo aquilo que uma casa de taipa traz de lembrança para estes e outros moradores do sul de Alagoas.

"Eu acho a casa de taipa mai segura do que a de tijolo, é mai segura porque ela é toda amarrada, com (...), de (...). tesoura, tudo, amarrada de cipó, lugar que tem prego, lugar de tudo, e a de tijolo não pega prego em canto nenhum. A casa de tijolo, depois dela rachar ela vai se embora, né?! E a casa de taipa ela aparta todinha, ela aparta as parede todinha e sendo bem feita, ela acenta no chão, e não cai." (Seu Bé, 2006)

Assim, a singularidade desse povoado reside no fato de ainda ser possível encontrar uma memória sobre os tempos coloniais, que se evidenciam não apenas no discurso dos moradores sobre fatos históricos relacionados ao sul de Alagoas, mas sobre práticas que venceram o tempo e sobre o significado atribuído a bens de significação como a técnica da taipa que pontua o cotidiano das pessoas de Poxim como sinal patrimonial que, oscilando entre a materialidade e a imaterialidade espelham a essência do singular povoado.

As pessoas que vivem em Poxim acumulam, comparam e comunicam experiências do morar e, neste sentido, a taipa se revela na paisagem de Poxim, porém não é apenas uma marca imóvel do patrimônio local.

Parte do processo construtivo, no linguajar local, é chamado "tapação", realizado em mutirão, contendo aspectos festivos e lúdicos, atreladas a cantigas e rituais, evidentes quando homens, mulheres e crianças misturam-se durante o trabalho coletivo de construção da morada. Enquanto o envarado das paredes é preenchido com barro, o beneficiário oferece bebida e comida aos parentes e amigos que cooperam nesta tarefa. Além de baratear os gastos, o tapamento desempenha importante papel na definição de laços de solidariedade entre as pessoas que cooperam nesta prática.

"Quando vai construi as casa de taipa. Aí o pessoal fazia o barro, o barreiro, fazia o barrero, e depois da, do barro feito se agarrava tudinho, os velho, as pessoa, os home um com o outo, e saia pizando o barro, cantando, cantando, tudo cantando e pizando o barro, né? (...) Os homens, né, sempre prá fazer o barrero, o barrero é ajuntá aquele bocado de barro, abre um buraco assim no meio, e a gente ia carregando água do rio tudo com um pote, e jogando ali naquele meio, né, do, do, barro. Aí eles iam misturando a água com o barro né, prá poder ligar. (...) Prá poder botar na parede. Mas nessa processo assim deles tá com a inchada traçando o barro, que nem faz massa prá reboco, né, fica traçando, traçando. Depois que, que traçava assim o barro, aí vinha aquela turma. Chamava as mulheres, prá gente ir, aí abraçava um com o outro, mulher e homem, tudo agarrado, e a gente cantava, repara que música-Me 
lembro que um tio meu., ele cantava assim - "Bora amassar o barro!" - a gente vinha aí cantava é: Eu vi o bico do sapato de/ Eu vi o bico do sapato de iá-iá/ Eu vi o bico do sapato/ Eu vi o bico do sapato da iá-iá/ Ô sinhá!/ Eu vi o bico do sapato de iu-iu" (Grupo de Mulheres, 2006)

"E era bonita a festa, era bonita, e a senhora quer ver bom, era na tapagem da parede, como ele falou, da casa, sim (...). Já, já, alcancei muita também, alcancei, alcancei muita tapagem de

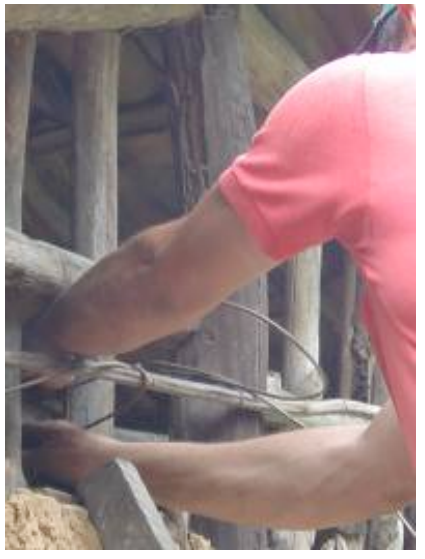

Fig. 2. O envarado (créditos: acervo do Grupo de Pesquisa Estudos da Paisagem, 2008)

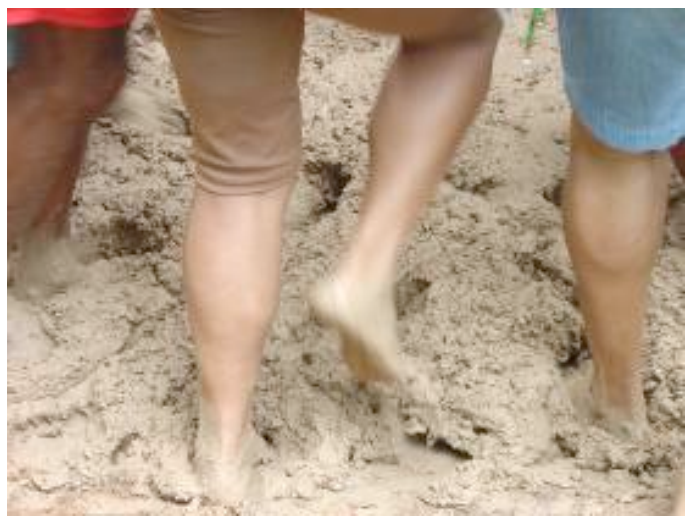

Fig. 3. As pessoas da comunidade pisando o barro para a tapação do envarado da casa de taipa (créditos: acervo do Grupo de Pesquisa Estudos da Paisagem, 2008)

casa, era lindo também, era, muito lindo, é. A parte mais bonita da tapação era o barreiro, o barreiro, é. O barreiro é onde cava o barro, sabe? Sim, faz o barro pra levar pra parede, é. Tem também o envarado, tem o pisoteamento pra

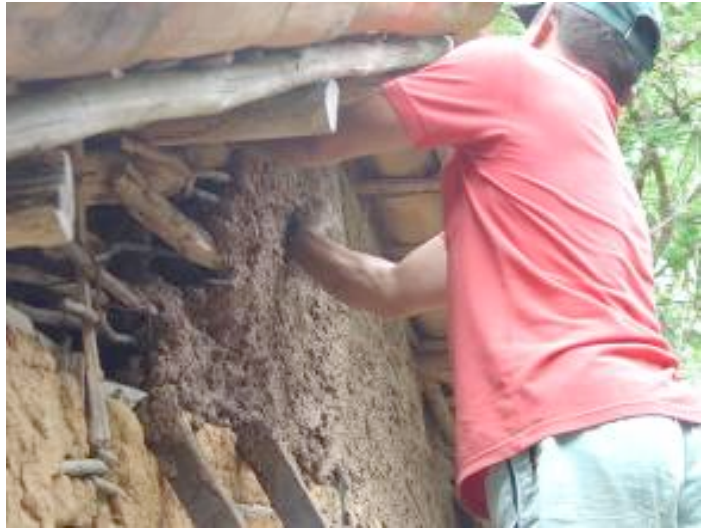

Fig. 4. A tapação da casa de taipa (créditos: acervo do Grupo de Pesquisa Estudos da Paisagem, 2008)

pisotear o barro... era pisar o barro e fazer o barro, era o mais bonito, da tapagem da casa, sabe? Sim, é." (Seu Bé, 2006)

\section{O REGISTRO DA TAIPA}

A investigação focou-se nos modos de fazer e modos de saber transmitidos de geração em geração através de mais de três séculos aferindo, portanto, a continuidade e a importância histórica de práticas certamente permeadas pela diversidade cultural que caracterizou a ocupação da região Nordeste como um todo. Para tanto, depreendemos que os dias que vivemos no presente também podem ser explicados pelos dias que os precederam. Visíveis ou não, sinais de um passado distante acrescentam à nossa realidade outras realidades.

Com o objetivo de identificar antigas práticas culturais ainda presentes nos hábitos dos moradores, essas informações imagéticas foram contrapostas com os cenários atuais das comunidades estudadas através de levantamento fotográfico e, especialmente, dos dados adquiridos através da oralidade dos membros dos povoados de Poxim. Este e outros localizados em áreas vizinhas, à primeira vista configuram-se como incipientes, com ruas indefinidas, casario singelo, habitados por pessoas simples. No entanto, guardam evidências de um passado distante, fragmentos de longa duração, concretos 


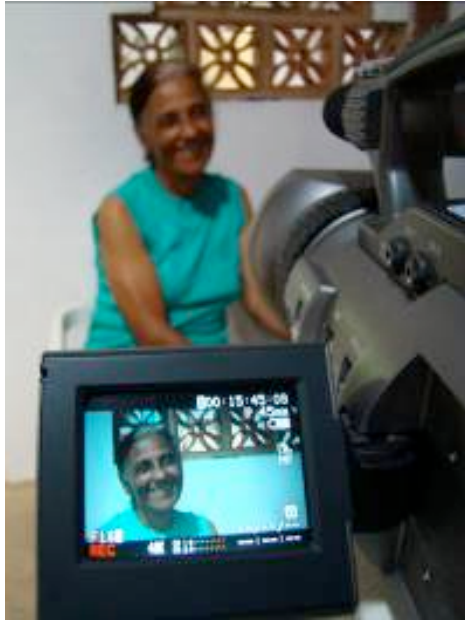

Fig. 5. Entrevista com Dona Anadeje (créditos: acervo do Grupo de Pesquisa Estudos da Paisagem, 2008)

e imaginários, que ainda pontuam a paisagem e a vida que a anima.

A relação construída no decorrer da pesquisa estabeleceu laços estreitos com os moradores facilitando a naturalidade dos depoimentos. Muitos moradores, como D. Anadeje, recebe a equipem em sua própria casa. Momentos espontâneos, como as cantigas, também foram resultado dessa familiaridade.

Durante o período do trabalho a equipe esteve em contato com os moradores em busca de registrar a construção de uma casa de taipa, do envarado ao tapamento. No entanto, no período de um ano de registro de práticas imateriais em Poxim, além dos depoimentos foi registrado apenas o retoque em uma casa já consolidada.

O processo de montagem do vídeo se deu pela curadoria dos depoimentos mais relevantes, com os trechos que representam a familiaridade com esse tipo de moradia. A elaboração de um texto narrativo aliado a uma trilha sonora de caráter regional delineou o formato do vídeo.

O vídeo inicia-se com um resgate dos tempos em que as casas de taipa eram destaque na paisagem do povoado. $\bigcirc$ processo de construção narrado é ilustrado por registros do retoque, guiado por

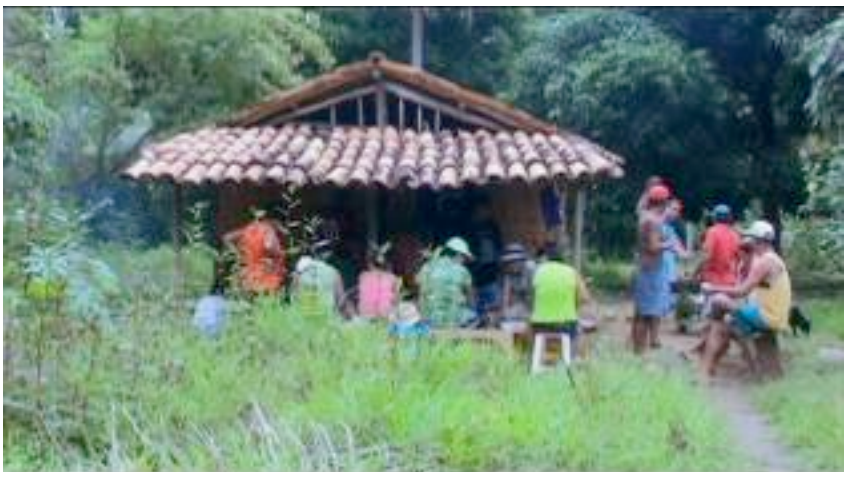

Fig. 6. O clima de festa durante o retoque. Trecho do vídeo "Coisas que a terra dá: a taipa no Poxim" (créditos: acervo do Grupo de Pesquisa Estudos da Paisagem, 2008)

depoimentos de seus próprios "fazedores" e cantigas que rememoram tempos onde essa prática se fazia mais presente. Durante o retoque, fragmentos são recobertos por um novo barro, resgatando a memória do trabalho coletivo e o clima de festa.

O processo de registro da taipa resultou em uma expressão espontânea de memórias e imagens concretas da presença forte dessa prática no povoado. Como contrapartida ao povoado, o vídeo foi exibido para a população na parede lateral da igreja de Poxim.

O ato de construir casa de taipa já não é uma prática comum ao dia a dia do povoado. "Coisas que a terra dá: a taipa no Poxim" trata da relação dos moradores com esse tipo de construção, ressaltando esse modo de viver que se eterniza na paisagem e na memória de seus moradores.

\section{Bibliografia}

Andrade-Lima, D. et al. (1986). O Herbário de Georg Marggraf (2 volumes). Rio de Janeiro: Fundação Nacional Pró-Memória; Recife: Fundação do Patrimônio Histórico e Artístico de Pernambuco.

Barléus, G. (1977). História dos Feitos Recentemente praticados durante oito anos no Brasil. São Paulo: Itatiaia Ed.

Bernardi, B. (1974). Introdução aos estudos etnoantropológicos. Lisboa: Edições 70.

Diegues, A. C. \& Arruda, R. S. V. (Orgs.) (2001). Saberes tradicionais e biodiversidade no Brasil. Brasília: Ministério do Meio Ambiente; São 
Paulo: USP.

Marcgrave, J. (1942). História natural do Brasil. São Paulo: Imprensa Oficial do Estado.

Piso, G. (1948). História Natural do Brasil llustrada. Trad. do Prof. Alexandre Correia. São Paulo: Companhia Editora Nacional.

Prestes, M. E. B. (2000). A Investigação da Natureza no Brasil Colônia. São Paulo: Annablume: Fapesp.

Souza, G. S. (1938). Tratado Descriptivo do Brasil em 1587. São Paulo/Rio de Janeiro/Recife/ Porto Alegre: Companhia Editora Nacional.

Nota

A pesquisa que embasou este artigo foi

desenvolvido com o apoio da Fundação Universitária de Desenvolvimento de Extensão

e Pesquisa da Universidade Federal de Alagoas

- FUNDEPES/ UFAL e com o financiamento

do Instituto do Patrimônio Histórico e Artístico Nacional - IPHAN. 